Pathologe 2020 41 (Suppl 1):S1-S8 https://doi.org/10.1007/s00292-019-0600-9 Published online: 4 July 2019

(c) The Author(s) 2019

\author{
M. S. Dettmer' $\cdot$ A. Schmitt' P. Komminoth ${ }^{2} \cdot$ A. Perren ${ }^{1}$ \\ 'Institute of Pathology, University of Bern, Bern, Switzerland \\ ${ }^{2}$ Institute of Pathology, City Hospital Triemli, Zürich, Switzerland
}

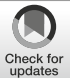

Check for
updates

\title{
Poorly differentiated thyroid carcinoma
}

\section{An underdiagnosed entity}

\section{Background}

Theodor Langhans described a malignant thyroid carcinoma in 1907, which he termed "rampantly goiter" or "wuchernde Struma" in German [30]. While this entity was well received in the German literature and textbooks [41], the term "poorly differentiated thyroid carcinoma" (PDTC) was first introduced by Granner and Buckwalter in the early 1960s to the English-speaking audience. At that time, clear diagnostic criteria were not provided [21].

With pathology developing a more criteria-based approach, two groups independently published different diagnostic criteria in 1983/1984 to allow for the diagnosis of PDTC [12, 44]. Sakamoto et al. postulated the frequency of PDTC at about $14 \%$ in a series of 258 thyroid carcinomas [44]. The other group referred to Langhans' so-called wuchernde Struma, which he introduced 1907 and which may in fact be the first description of a PDTC in the literature [12].

The two schools of thought remained: While one school placed more emphasis on the growth pattern of the lesion (trabecular, insular, or solid), the other group used typical features of high-grade lesions like atypia, tumor necrosis, or a high mitotic index $[1,12,38,44,49$, 54]. It took another 20 years for this entity to be accepted and introduced in the World Health Organization (WHO) series of malignant human neoplasms in

The German version of this article can be found under https://doi.org/10.1007/s00292019-0613-4.
2004 [13] and since then it has been a recognized entity [33].

Both of the aforementioned groups recognized the concept of a thyroid tumor that is placed biologically between well-differentiated thyroid carcinomas like papillary thyroid carcinomas (PTC) or follicular thyroid carcinomas (FTC) with an excellent prognosis and the extremely aggressive anaplastic thyroid carcinomas (ATC; [36]). However, both groups offered significant different diagnostic approaches to allow for such a diagnosis. Obviously, different diagnostic algorithms and criteria led to an increased uncertainty of these lesions and, consequently, studies were not comparable. While some integrated tumors that we would classify as PDTC today, others also included the tall cell variant of PTC, which today would fall into the category of well-differentiated thyroid carcinomas (however, with an adverse outcome; [27, 45]).

\section{Diagnostic algorithm}

In order to unify the concepts of PDTC, a group of internationally recognized thyroid experts met in 2006 in Turin and elaborated the so-called Turin criteria, which are a diagnostic algorithm, based on both schools of thought: high-grade features and growth pattern (• Fig. 1 and 2; [53]). This algorithm is now accepted and integrated in the WHO classification [33].

After identification of malignancy (angioinvasion and/or gross invasion), a so-called STI pattern (solid, trabecular, or insular growth pattern) is the first hint of the diagnosis of PDTC. It is worth pointing out that PDTC may on rare occasions be completely encapsulated and even without angioinvasion. These cases are prone to be misdiagnosed as adenomas if the pathologist in charge is not familiar with the concept of PDTC.

One has to look for PTC nuclei throughout the lesion in order to exclude the solid variant of PTC. If this feature is absent, one of the three following features is enough to allow for the diagnosis of a PDTC to be made:

1. convoluted nuclei that are a bit smaller than those of a PTC while also having a wrinkled irregular contour that overall gives them a raisinoidlike appearance. Nevertheless, their chromatin is much darker and evenly distributed and their overall appearance is more uniform than in PTC nuclei. Nuclear pseudoinclusions are absent while one may observe some nuclear grooves. If pseudoinclusions are present, they may be seen as a sign of tumor progression from a PTC to a PDTC, and if enough tumor material is embedded, classic PTC remnants may be seen in such cases [36].

2. Tumor necrosis also allows for the diagnosis of a PDTC in this flowchart, usually seen as a small necrotic focus within a solid tumor cell nest. Single cell necrosis does not count, and it is essential to exclude tumor necrosis followed by fine-needle aspiration (FNA), which happens frequently especially in oncocytic nodules.

3. The last criterion is an increased mitotic activity of at least three mitoses 


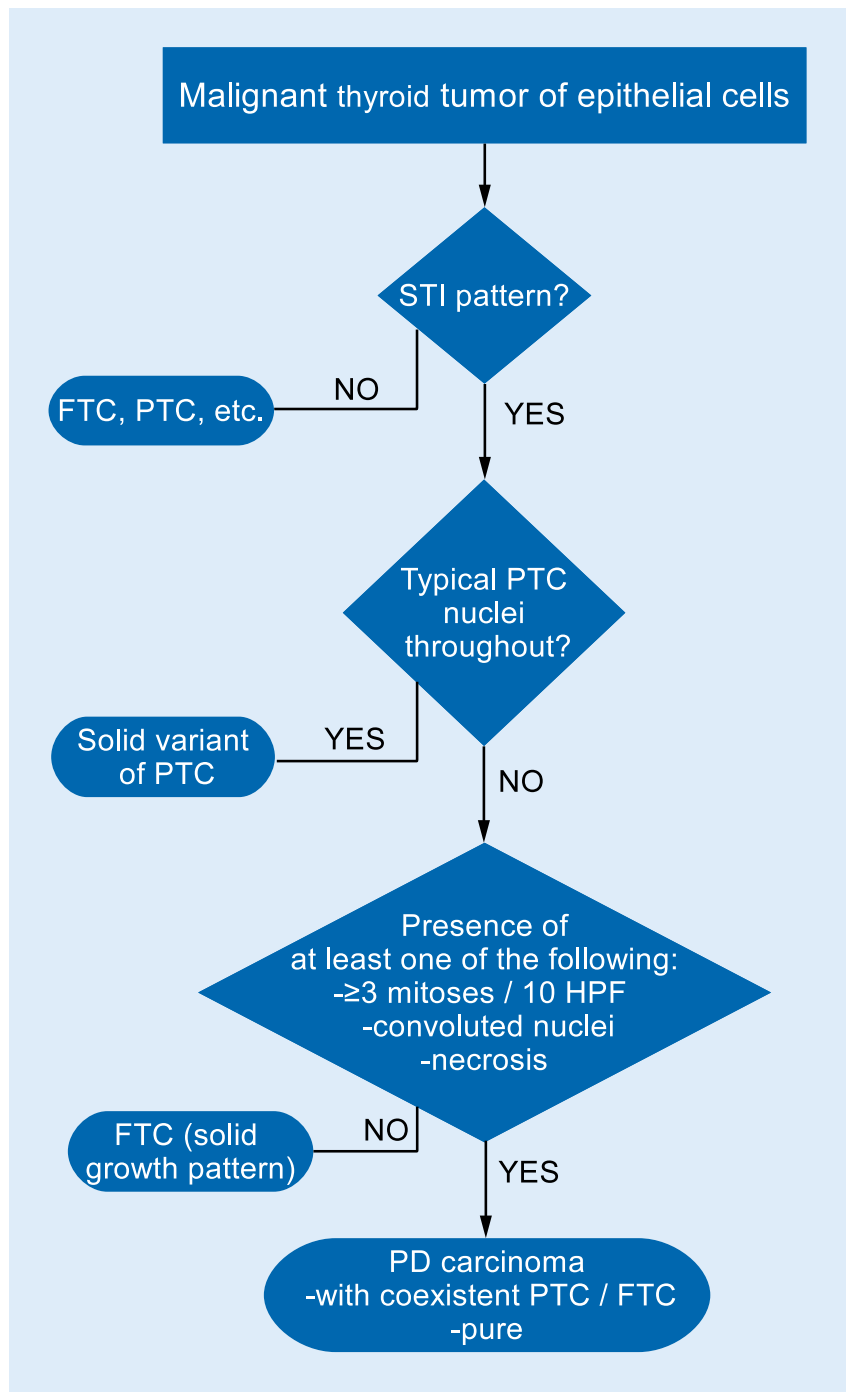

series, only $27 \%$ of cases were diagnosed correctly as PDTC on FNA $[3,5,28$, 40], whereas most of the remaining cases were put into the category "(suggestive of) follicular neoplasm"[6]. According to a recent review and meta-analysis of the literature by Saglietti et al., the presence of insular or solid architecture, hypercellularity, high nuclear/cytoplasmic ratio, and mitotic activity can suggest the diagnosis of PDTC [43].

\section{How much "poorly differentiated" is needed?}

Fig. $1<$ Diagnostic algorithm for the diagnosis of a poorly differentiated thyroid carcinoma (PDTC). FTC follicular thyroid carcinomas, PTC papillary thyroid carcinomas, STI solid, trabecular, or insular growth, $P D$ poorly differentiated, HPF high power field per ten high-power fields. This cutoff exhibited a good correlation with survival data in the cases used in the Turin consensus meeting; however, the amount of mitosis per $\mathrm{mm}^{2}$ needed was unfortunately not defined [54].

Applying the correct Turin criteria, PDTCs are-as already indicated in the title-rare lesions. Over a time span of 26 years and in a population of 1.37 million inhabitants, we were able to identify 34 PDTC carcinomas [15]. In that study, only one tumor was diagnosed as PDTC in the original pathology report, indicating that the concept of PDTC is not yet well known and must be used more widely in everyday practice [14].

Currently, the incidence of PDTC in Europe is estimated at $4-7 \%$ of all thyroid carcinomas, which corresponds to 240 new cases in Germany each year.

The incidence of indolent thyroid carcinomas has been rising for many years and as a consequence many patients get overtreated [34]. On the other hand, PDTCs, which require a correct diagnosis in order to receive adequate treatment, are often missed in daily routine.

\section{Fine-needle aspiration}

The cytological diagnosis of PDTC on FNA samples is challenging. This is due to the rareness of the diagnosis, the nonspecific cytological features, the overlap with cytological characteristic of follicular neoplasms, and the frequently encountered sampling error of the PD component in an otherwise well-differentiated tumor. Thus, according to published
It has long been known that there are PDTCs with a minor and even a major component of a well-differentiated thyroid carcinoma like PTC or FTC. Today, it is believed that most of them arise in a well-differentiated thyroid carcinoma, although a subset of these lesions apparently also arise de novo (• Fig. 3). About $80 \%$ of PDTC have a PD component of $>50 \%$, and only $20 \%$ of PDTC have a minor PD component [14]. However, it was unclear in the Turin proposal what percentage of poorly differentiated was needed in a tumor to allow for such a diagnosis and-more importantly-to affect patient prognosis; moreover, the 2004 WHO classification did not offer a cut-off value [13]. We showed that even a small PD component of $10 \%$ affects patient prognosis equally negative as a tumor that consists of $100 \%$ PD regarding relapse-free survival or overall survival $[14,33]$. Our findings were recently confirmed by others [4] and are now reflected in the current WHO classification [33]. Therefore, a thorough histological workup is highly recommended to ensure an adequate diagnosis is made.

\section{Oncocytic subtype-does it matter?}

Based on their neoplastic tumor of origin, PDTCs can be subdivided into papillary type, follicular type, and not otherwise specified (NOS). However, this subdivision does not have any clinical or prognostic consequences [36].

Owing to a lack of data, oncocytic carcinomas were excluded in the Turin proposal and therefore it was initially un- 
known whether these criteria were also applicable to oncocytic lesions. We reported that the Turin criteria can also be applied in this scenario [15]. However, it should be emphasized that the presence of necrosis in these tumors should not be overestimated since oncocytic lesions in general are prone to spontaneous or FNA-initiated infarction and focal necrosis. Thus, one should carefully look for signs of previous FNA in a given case. And while the relapse-free survival is similar between PDTC and oncocytic PDTC, it is nevertheless very important to distinguish between PDTC and oncocytic PDTC, since oncocytic PDTC may have an even worse overall survival than conventional PDTC [15].

\section{Differential diagnoses}

Poorly differentiated thyroid carcinoma must be distinguished from malignant lesions that are not derived from follicular epithelial cells such as medullary thyroid carcinomas or rarely metastases to the thyroid, most often derived from the kidney or lung [36]. Also, well-differentiated thyroid carcinomas like PTC and especially the solid variant of PTC needs to be excluded on the basis of nuclear features. The same is true for FTCs that do not show an STI pattern. Of note, many lesions that have been classified as widely invasive FTC in the past, today fall into the category of PDTC. And while there is a progression from well-differentiated thyroid carcinomas to PDTC, there may also be a further progression to an ATC that of course is prognostically relevant and even the smallest ATC component should be reported as well $[50,51]$.

\section{TNM classification}

The current 8 th edition of the TNM classification was introduced in 2017. Now, all thyroid carcinomas including ATC are similarly categorized into different tumor stages [9]. One study explored the validity of the new classification and while it seems that a good prognostic separation for FTC can be achieved, neither the 7th nor the 8th edition is able to predict accurately patient prognosis for PDTC [26].

Pathologe 2020 - 41 (Suppl 1):S1-S8 https://doi.org/10.1007/s00292-019-0600-9

(C) The Author(s) 2019

M. S. Dettmer · A. Schmitt · P. Komminoth · A. Perren

\section{Poorly differentiated thyroid carcinoma. An underdiagnosed entity}

Abstract

Poorly differentiated thyroid carcinomas (PDTCs) are a rare subtype of thyroid carcinomas that are biologically situated between well-differentiated papillary/follicular thyroid carcinomas and anaplastic thyroid carcinomas (ATCs).

The diagnosis of conventional as well as oncocytic poorly differentiated thyroid carcinoma is difficult and often missed in daily routine. The current $\mathrm{WHO}$ criteria to allow the diagnosis of PDTCs are based on the results of a consensus meeting held in Turin in 2006. Even a minor poorly differentiated component of only $10 \%$ of a given carcinoma significantly affects patient prognosis and the oncocytic subtype may even have a worse outcome. Immunohistochemistry is not much help and is mostly used to exclude a medullary thyroid carcinoma with calcitonin and to establish a follicular cell of origin via thyroglobulin staining.
Due to the concept of stepwise dedifferentiation, there is a vast overlap of different molecular alterations like BRAF, RAS, CTNNB1, TP53 and others between different thyroid carcinoma subtypes. A distinctive molecular tumor profile is therefore currently not available.

PDTCs have a unique miRNA signature, which separates them from other thyroid carcinomas. The average relapse free survival is less than one year and about $50 \%$ of patients die of the disease. Modern tyrosine kinase inhibitors offer in conjunction with powerful molecular diagnostic new chances in these difficult to treat carcinomas.

\section{Keywords}

Poorly differentiated thyroid carcinoma . MicroRNA - Prognosis - Thyroid neoplasm . Tyrosine kinase inhibitor

\section{Gering differenzierte Schilddrüsenkarzinome. Eine unterdiagnostizierte Entität}

\section{Zusammenfassung}

Gering differenzierte Schilddrüsenkarzinome (PDTC) stellen einen seltenen Subtyp des Schilddrüsenkarzinoms dar, welcher biologisch zwischen den gut differenzierten Schilddrüsenkarzinomen (papilläre und follikuläre Schilddrüsenkarzinome) auf der einen Seite und den anaplastischen Schilddrüsenkarzinomen auf der anderen Seite angesiedelt ist.

Die Diagnose des konventionellen wie des onkozytären PDTC ist schwierig und wird in der täglichen Routine oft verpasst. Derzeit werden diese Tumoren nach Kriterien der aktuelle WHO-Klassifikation diagnostiziert, welche in einer Konsensustagung 2006 in Turin erarbeitet wurden. Selbst ein kleiner Anteil eines PDTC von nur $10 \%$ innerhalb eines Schilddrüsenkarzinoms beeinflusst die Prognose nachhaltig und die onkozytäre Variante hat einen nochmals ungünstigeren Verlauf. Immunhistochemische Analysen sind meist nicht hilfreich und werden genutzt, um ein medulläres Schilddrüsenkarzinom mittels Calcitonin auszuschließen oder die
Follikelepithelzelle als Ursprungszelle mittels Thyreoglobulin nachzuweisen. Auf molekularer Ebene gibt es eine große Überlappung unterschiedlicher Mutationen in den verschiedenen Schilddrüsenkarzinomen wie BRAF, RAS, CTNNB1 oder TP53, welche sich durch das Konzept der schrittweisen Dedifferenzierung gut erklären lassen. Entsprechend existiert nach wie vor kein eigenständiges, für die Diagnostik einsetzbares molekulares Profil. PDTC haben ein distinktes miRNA-Profil im Vergleich zu anderen Schilddrüsenkarzinomen. Das durchschnittliche rezidivfreie Überleben liegt unter einem Jahr und etwa 50\% der Patienten versterben an ihrem Tumor. Thyrosinkinaseinhibitoren eröffnen gemeinsam mit einer leistungsstarken molekularen Diagnostik neue Therapiechancen in diesen schwer zu therapierenden Karzinomen.

\section{Schlüsselwörter}

Gering differenziertes Schilddrüsenkarzinom . MicroRNA · Prognose - Schilddrüsentumor . Thyrosinkinaseinhibitor 

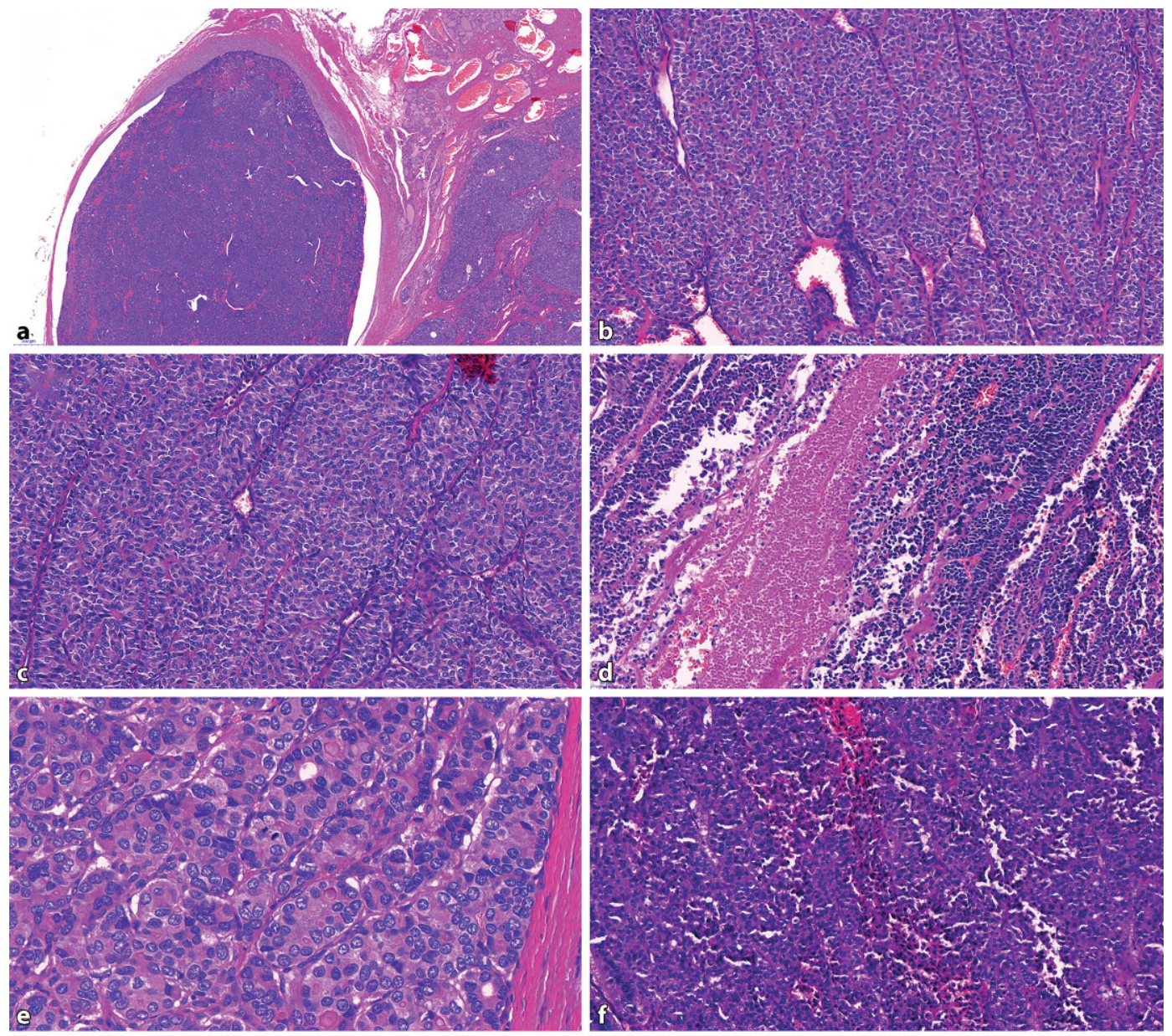

Fig. $2 \triangleleft$ a Obviously malignant neoplasm, vascular invasion and invasion into adjacent tissue; $\mathbf{b}$ trabecular growth pattern; c insular and solid growth pattern;
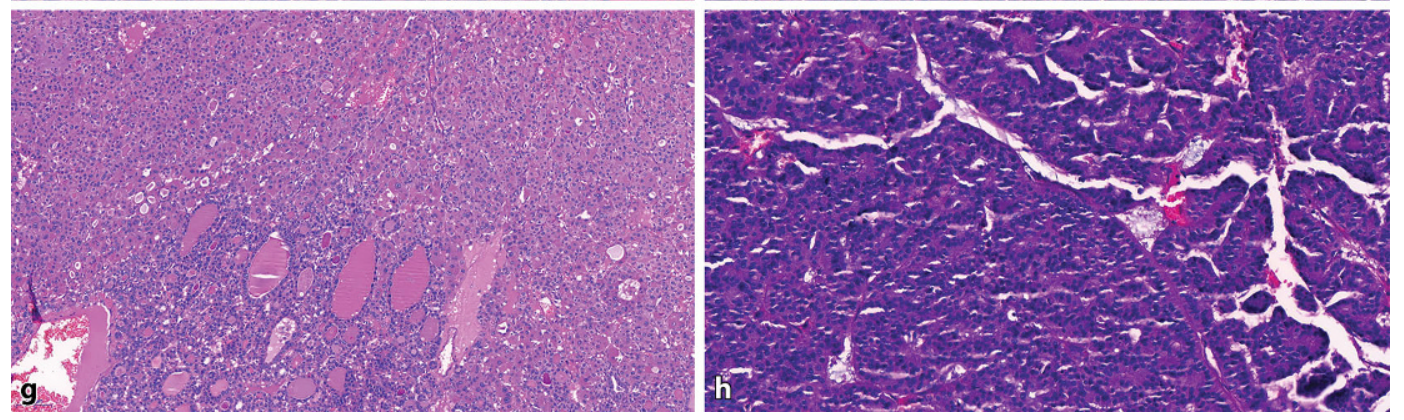
d tumor necrosis; e mitosis and psammoma bodies, no papillary thyroid carcinomas (PTC) nuclei; fraisinoid nuclei, trabecular growth pattern; $\mathbf{g}$ upper part oncocytic poorly differentiated thyroid carcinoma (PDTC), lower part FTC; $\mathrm{h}$ PTC remnants in a PDTC. Only architecture of PTC, no longer any PTC nuclei

\section{Immunohistochemistry}

Immunohistochemical studies in thyroid carcinomas in general and in PDTC in particular have been performed [31] and results are summarized in 0 Table 1 . It can be of help to establish a follicular cell of origin and exclude a medullary thyroid carcinoma, which would stain positive for calcitonin [20] and neuroendocrine markers [31]. Poorly differentiated thyroid carcinomas are typically positive for thyroglobulin, although the expression is often patchy and focal $[2,37]$. Strong and diffuse positivity of thyroglobulin is typically found in the adjacent well-differentiated carcinoma component.

Most of the diagnostic work-up, however, is based on classic hematoxylin-eosin staining. Markers of malignancy in thyroid carcinomas like Galectin-3 or HBME-1 have been explored, but there is no practical application because signs of malignancy need to be present unequivocally in the first step to enter the Turin criteria $[2,31$, 39, 54]. Thus, CD31 staining or similar vascular markers to substantiate angioinvasion are probably more helpful than the aforementioned other antibodies.
About $40-70 \%$ of PDTC express TP53-which does not always correlate with the mutational TP53 gene status-and an immunohistochemical loss of the tumor suppressors p21 and p27 has also been observed $[2,31,36]$.

\section{Molecular alterations}

$B R A F$ mutations are seen in PDTC in about $20 \%$ of cases and RAS mutations in $20-40 \%$. Both mutations can, however, also be found in PTC and FTC ([35]; - Fig. 3). The activation of MAPK and PI3K-AKT signaling pathways is im- 


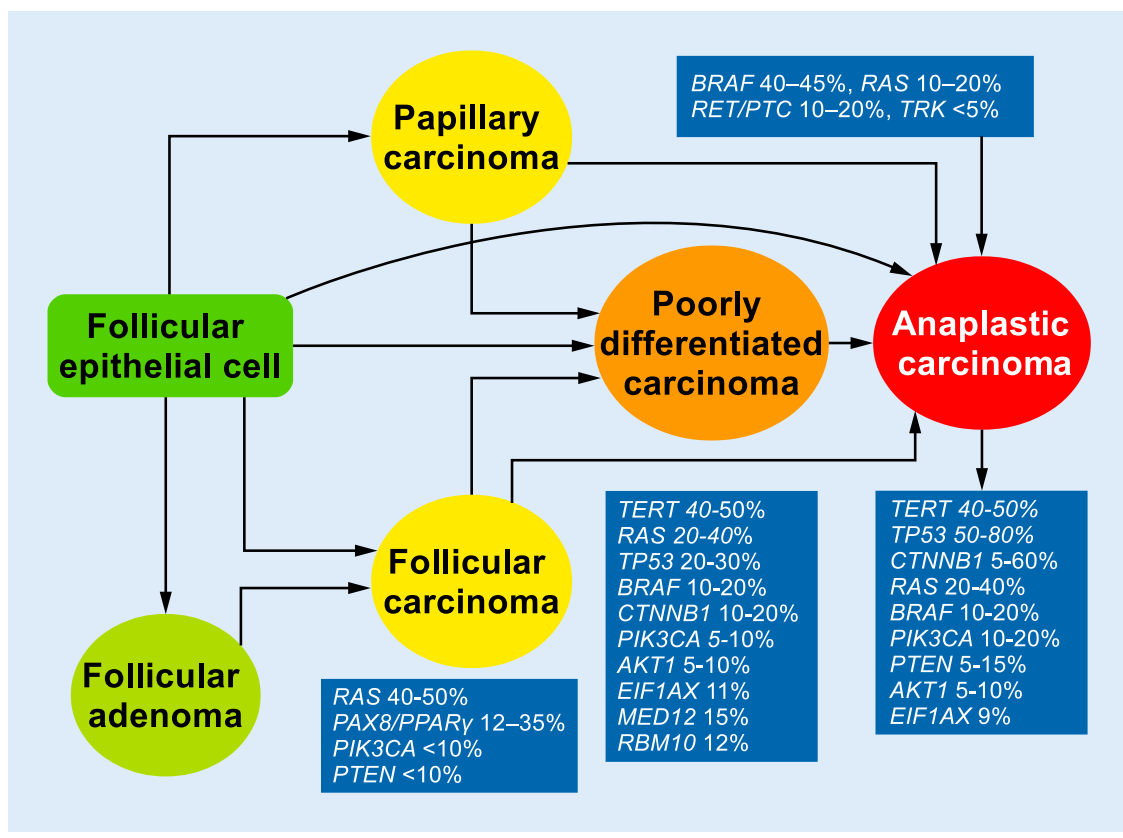

Fig. 3 a Stepwise de-differentiation of thyroid carcinomas derived from follicular epithelial cell

portant for thyroid cancer initiation and progression. Consistent with this notion, mutations in PIK3CA can be found in a subset of FTC (10\%) and in PDTC cases (5-10\%; [36]).

Mutations in the tumor suppressor gene TP53 and EIF1AX are thought to represent a late event in thyroid tumorigenesis and can be detected in about 30\% and $11 \%$ of PDTC cases $[29,35]$. These mutations occur basically only in advanced thyroid carcinomas (PDTC and ATC) and are almost never found in welldifferentiated lesions like PTC or FTC $[11,35]$. The other mutation that is a putative late event in thyroid cancer progression is CTNNB1, which is never found in well-differentiated cancers but in PDTC in about $10-20 \%$ and in ATC in up to $60 \%$ of cases. Mutations in MED12 and $R B M 10$ are recently described mutations in PDTC occurring in $12-15 \%$ of cases and may represent novel markers of aggressiveness [23].

Telomerase reverse transcriptase (TERT) promoter mutations have been reported in various thyroid malignancies and are always associated with an adverse outcome, probably due to an increased telomerase activity $[19,32]$. They occur in two exclusive hotspots, C228T and C250T, with a frequency of $33.8 \%$ and
$15 \%$, respectively, in PDTC, according to a meta-analysis [32].

Rearrangements are found in 10-14\% of PDTCs. These include rearrangements of RET/PTC, BRAF, ALK, NTRK3, and $P A X 8-P P R y$ [57], which can be encountered in about $7 \%$ of cases according to one study [7], while $R E T / P T C$ rearrangements also seem to be-if at all-only evident in a small percentage of cases [48]. These alterations are more frequently found in well-differentiated tumors-PAX8-PPR $\gamma$ in FTC in about $12-30 \%$ and RET-PTC in PTC in 10-20\% of cases $[7,36]$. It is possible, but yet to be proven, that these clones are less aggressive and usually become outgrown by more aggressive tumor parts with other mutations and are therefore rarely found in PDTC.

Owing to the vast overlap of mutations in the different subtypes and the lack of specific mutations, molecular testing of PDTC as a diagnostic tool has not found its way into clinical practice so far. However, the deeper insight into the molecular alterations and the new tyrosine kinase inhibitors will most likely change this in the very near future to ensure adequate patient treatment.

Comparative genomic hybridization (CGH) shows large numbers of chromosomal abnormalities in thyroid can- cers. Gains of 5p15, 5q11-13, 19p, and $19 q$ and loss of $8 p$ suggest that these tumors have a common signaling pathway and origin, while gains of 1p34-36, 6p21, 9q34, 17q25, and 20q and losses of 1p11-p31, 2q32-33, 4q11-13, 6q21, and 13q21-31 most likely represent secondary events of progression as they are only found in PDTC and ATC. Finally, gains at 3p13-14 and 11q13 and loss of 5q11-31 are only found in ATC [56]. In short, the number of gains and losses in PDTC are in the range between well-differentiated thyroid carcinomas and ATC, which have-unsurprisingly-the most alterations [42, 56].

\section{Epigenetic changes}

MiRNA expression in poorly differentiated carcinomas has been explored and we know today that PDTCs have a miRNA profile that is not only distinctive from well-differentiated thyroid carcinomas but that also separates PDTC from oncocytic PDTC [16-18]. The concept of tumor progression from PTC and FTC to PDTC can also be observed on the miRNA level where several miRNAs known to be upregulated in thyroid cancer like miR-221 and miR-222 are increasingly deregulated in PDTC as compared with PTC [18].

Long non-coding RNAs (lncRNAs) are other non-protein coding transcripts longer than 200 nucleotides that regulate proliferation and tumor recurrence. Initial evidence shows that lncRNAs may be involved in thyroid tumor progression and that they play a role in $B R A F$ regulation and in the MAPK pathway [46].

\section{Prognosis}

Poorly differentiated thyroid carcinomas are aggressive lesions that require appropriate diagnosis, treatment, and follow-up. The relapse-free survival is less than 12 months, the mean survival is $50-60$ months, and $44 \%$ of patients die of disease [2, 14]. Several factors have been identified to affect patient prognosis. Among them are increased patient age of $\geq 45$ years, large tumor size of $\geq 5 \mathrm{~cm}$, macroscopically evident extrathyroidal extension at surgery and dis- 


\begin{tabular}{llllll}
\hline \multicolumn{7}{l}{ Table 1} & Immunohistochemistry in different thyroid carcinomas \\
Immunohistochemical staining & MTC & PTC & FTC & PDTC & ATC \\
\hline Calcitonin & ++ & - & - & - & - \\
\hline Chromogranin A & ++ & - & - & no data & - \\
\hline Synaptophysin & ++ & $-/+$ & $-/+$ & no data & - \\
\hline Thyroglobulin & - & +++ & +++ & $-/+$ & $-/+$ \\
Galectin-3 & $-/+$ & ++ & $-/+$ & $-/+$ & $-/+$ \\
HBME-1 & $-/+$ & ++ & $-/+$ & $-/+$ & $-/+$ \\
PanCK & ++ & ++ & ++ & + & $-/+$ \\
TTF1 & ++ & ++ & ++ & $-/+$ & - \\
CK7 & ++ & ++ & ++ & $-/+$ & $-/+$ \\
CK19 & $-/+$ & ++ & $-/+$ & $-/+$ & - \\
PAX8 & - & ++ & $-/+$ & $-/+$ & $-/+$ \\
MTC medullary thyroid carcinoma, PTC papillary thyroid carcinoma, FTC follicular thyroid carcinoma, \\
PDTC poorly differentiated thyroid carcinoma, ATC anaplastic thyroid carcinoma \\
\hline
\end{tabular}

tant metastases at presentation [33], immunohistochemical markers like insulinlike growth factor mRNA-binding protein 3 (IMP3) and tumor necrosis factor [2].

The mutational landscape of PDTC continues to be deciphered and the identified molecular markers of aggressiveness are TERT promoter, MED12, RBM10, BRAF, HRAS, TP53, ATM, and EIF1AX mutations [24, 32, 55]. Deregulation in the expression of miR-23b and miR-150, both well-known tumorassociated miRNAs, also seem to play a role in PDTC and are suitable for predicting patient outcome [18].

The oncocytic subtype may be associated with an even worse clinical outcome than conventional PDTC, possibly due to a decreased radioiodine uptake that is typical for oncocytic lesions in general [15].

\section{Treatment}

There is no standardized treatment for PDTC to date. However, it is accepted that in general terms a more aggressive approach is needed to treat these tumors as compared with standard low-risk thyroid carcinomas [59]. If possible, a total thyroidectomy including lymph node dissection should be performed. According to one study, total thyroidectomy and removal of residual disease achieved a 5year regional control of $81 \%$ [22]. Radioiodine treatment is only successful in a subset of patients owing to variable lev- els of iodine uptake, although the exact number of responders is unclear. Nevertheless, given the high mortality rate of the neoplasm and the potential therapeutic benefit, high-dose radioiodine treatment is currently recommended for all PDTC patients by a multidisciplinary group of experts [45]. The same authors recommend external beam radiation for large tumors of $>4 \mathrm{~cm}$ with stage $\mathrm{T} 3$ and T4 and for patients with regional lymph node metastases [45]. However, little has been published on PDTC and external beam radiation and recommendations are solely based on extrapolation from studies of well-differentiated thyroid carcinomas (PTC/FTC) where a treatment benefit could be shown in patients who are at high risk of local recurrences [8]. Chemotherapy is currently not standard of care, although positive effects have rarely been observed in some patients [58]. By contrast, the role of tyrosine kinase inhibitors is evolving and they may be a new and promising approach for treating PDTC in the future. In fact, after the results of the DECISION and the SELECT trial were published, sorafenib and lenvatinib were approved by the U.S. Food and Drug Administration (FDA) for patients with radioiodine-resistant progressive, recurrent, or metastatic disease [10, 25, 47]. However, we still do not know whether a specific molecular signature predicts response to also unknown whether patients should be treated in early or late stages, and the a given tyrosine kinase inhibitor. It is actual benefit in terms of patient survival remains to be seen [52].

\section{Summary}

Poorly differentiated thyroid carcinomas are aggressive lesions that severely impact patients' life and a correct diagnosis is central for further patient management.

The Turin criteria, the diagnostic algorithm facilitating a diagnosis of PDTC, were established more than 10 years ago and since then their utility has been proven in multiple studies. The former uncertainty among pathologists with these lesions should be resolved and PDTCs are now accepted as a separate entity in the current WHO classification. Some studies of epigenetic changes are available and loss and gains of different chromosomes as well as miRNA deregulation seem to be involved in the development of PDTC. Despite our growing knowledge on molecular alterations in the thyroid, molecular pathology has currently no central role as a diagnostic tool of PDTC, mostly owing to the concept of stepwise thyroid cancer progression. Nevertheless, the role of molecular pathology in conjunction with new tyrosine kinase inhibitors will become increasingly important to ensure adequate treatment in the era of personalized medicine.

\section{Practical conclusion}

- Poorly differentiated thyroid car-
cinomas are an underdiagnosed
entity.
- An increased mitotic index and tumor
necrosis in conjunction with a solid
trabecular or insular growth pattern
as described in the Turin proposal can
reliably differentiate between a well-
differentiated thyroid carcinoma
and a poorly differentiated thyroid
carcinoma.
A poorly differentiated area of only
$10 \%$ within a thyroid carcinoma will
significantly affect patient prognosis.
Tyrosine kinase inhibitors offer new
treatment options in these very
difficult to treat tumors.




\section{- Molecular mutational testing will help in decision-making for targeted therapies.}

\section{Corresponding address}

PD Dr. M. S. Dettmer

Institute of Pathology, University of Bern

Murtenstraße 31, 3010 Bern, Switzerland

dettmerms@gmail.com

Matthias.Dettmer@pathology.unibe.ch

\section{Compliance with ethical guidelines}

Conflict of interest M. S. Dettmer, A. Schmitt, P. Komminoth, and A. Perren declare that they have no competing interests.

For this article no studies with human participants or animals were performed by any of the authors. All studies performed were in accordance with the ethical standards indicated in each case.

The supplement containing this article is not sponsored by industry.

Open Access This article is distributed under the terms of the Creative Commons Attribution 4.0 International License (http://creativecommons.org/licenses/by/ 4.0/), which permits unrestricted use, distribution, and reproduction in any medium, provided you give appropriate credit to the original author(s) and the source, provide a link to the Creative Commons license, and indicate if changes were made.

\section{Literatur}

1. Akslen LA, Livolsi VA (2000) Poorly differentiated thyroid carcinoma-It is important. Am J Surg Pathol 24:310-313

2. Asioli S, Erickson LA, Righi A et al (2010) Poorly differentiated carcinoma of the thyroid: Validation of the Turin proposal and analysis of IMP3 expression. Mod Pathol 23:1269-1278

3. Barwad A, Dey P, Nahar Saikia U et al (2012) Fine needle aspiration cytology of insular carcinoma of thyroid. Diagn Cytopathol 40(S1):E43-E47

4. Bichoo RA, Mishra A, Kumari N et al (2019) Poorly differentiated thyroid carcinoma and poorly differentiated area in differentiated thyroid carcinoma: Is there any difference? Langenbecks Arch Surg 404(1):45-53

5. Bongiovanni M, Bloom L, Krane JF et al (2009) Cytomorphologic features of poorly differentiated thyroid carcinoma: A multi-institutional analysis of 40 cases. Cancer Cytopathol 117:185-194

6. Bongiovanni M, Faquin WC (2010) Poorly differentiated thyroid carcinoma. In: Ali SZ, Cibas E (eds) The Bethesda system for reporting thyroid cytopathology. Springer, New York, pp 129-138

7. Boos LA, Dettmer M, Schmitt A et al (2013) Diagnostic and prognostic implications of the PAX8-PPARgamma translocation in thyroid carcinomas-A TMA-based study of 226 cases. Histopathology 63:234-241
8. Brierley J, Tsang R, Panzarella T et al (2005) Prognostic factors and the effect of treatment with radioactive iodine and external beam radiation on patients with differentiated thyroid cancer seen at a single institution over 40 years. Clin Endocrinol (Oxf) 63:418-427

9. Brierley JD, Gospodarowicz MK, Wittekind C (eds) (2017) TNM classification of malignant tumours, 8 edn. Wiley-Blackwell, Hoboken

10. Brose MS, Nutting CM, Jarzab B et al (2014) Sorafenib in radioactive iodine-refractory, locally advanced or metastatic differentiated thyroid cancer: A randomised, double-blind, phase 3 trial. Lancet 384(9940):319-328

11. Cancer Genome Atlas Research Network (2014) Integrated genomic characterization of papillary thyroid carcinoma. Cell 159(3):676-690

12. Carcangiu ML, Zampi G, Rosai J (1984) Poorly differentiated ("insular") thyroid carcinoma. A reinterpretation of Langhans' „wuchernde Struma". Am J Surg Pathol 8:655-668

13. Delellis R, Lloyd R, Heitz P, Eng C (eds) (2004) Pathology and genetics of tumours of endocrine organs, 3 edn. World Health Organization classification of tumours, vol 8. IARC, Lyon

14. Dettmer M, Schmitt A, Steinert Het al (2011) Poorly differentiated thyroid carcinomas: How much poorly differentiated is needed? Am J Surg Pathol 35:1866-1872

15. Dettmer M, Schmitt A, Steinert $H$ et al (2012) Poorly differentiated oncocytic thyroid carcinoma-Diagnostic implications and outcome. Histopathology 60:1045-1051

16. Dettmer M, Perren A, Moch H et al (2013) Comprehensive MicroRNA expression profiling identifies novel markers in follicular variant of papillary thyroid carcinoma. Thyroid 23:1383-1389

17. Dettmer $M$, Vogetseder A, Durso $M B$ et al (2013) MicroRNA expression array identifies novel diagnostic markers for conventional and oncocytic follicular thyroid carcinomas. J Clin Endocrinol Metab 98:E1-7

18. Dettmer MS, Perren A, Moch H et al (2014) MicroRNA profile of poorly differentiated thyroid carcinomas: New diagnostic and prognostic insights. J Mol Endocrinol 52:181-189

19. Dettmer MS, Schmitt A, Steinert H et al (2015) Tall cell papillary thyroid carcinoma: New diagnostic criteria and mutations in BRAF and TERT. Endocr Relat Cancer 22:419-429

20. Erickson LA, Lloyd RV (2004) Practical markers used in the diagnosis of endocrine tumors. Adv Anat Pathol 11:175-189

21. Granner DK, Buckwalter JA (1963) Poorly differentiated carcinoma of the thyroid gland. Surg Gynecol Obstet 116:650-656

22. Ibrahimpasic T, Ghossein R, Carlson DL et al (2014) Outcomes in patients with poorly differentiated thyroid carcinoma. J Clin Endocrinol Metab 99:1245-1252

23. Ibrahimpasic T, Xu B, Landa l et al (2017) Genomic alterations in fatal forms of non-anaplastic thyroid cancer: Identification of MED12 and RBM10 as novel thyroid cancer genes associated with tumor virulence. Clin Cancer Res 23:5970-5980

24. Ibrahimpasic T, Ghossein RM, Shah JP et al (2019) Poorly differentiated carcinoma of the thyroid gland: Current status and future prospects. Thyroid 29(3):311-321

25. National Cancer Institutehttps://www.cancer.gov/ about-cancer/treatment/drugs/thyroid. Accessed 14 Febr 2019

26. Ito Y, Miyauchi A, Hirokawa M et al (2018) Prognostic value of the 8 (th) tumor-node- metastasis classification for follicular carcinoma and poorly differentiated carcinoma of the thyroid in Japan. Endocr J 65:621-627

27. Jung TS, Kim TY, Kim KW et al (2007) Clinical features and prognostic factors for survival in patients with poorly differentiated thyroid carcinoma and comparison to the patients with the aggressive variants of papillary thyroid carcinoma. Endocr J 54:265-274

28. Kane SV, Sharma TP (2015)Cytologic diagnosticapproach to poorly differentiated thyroid carcinoma: A single-institution study. Cancer Cytopathol 123:82-91

29. Landa I, Ibrahimpasic T, Boucai L et al (2016) Genomic and transcriptomic hallmarks of poorly differentiated and anaplastic thyroid cancers. JClin Invest 126:1052-1066

30. Langhans T (1907) Über die epithelialen Formen der malignen Struma. Virchows Arch Pathol Anat Physiol Klin Med 189:69-152

31. Lin F, Prichard J (eds) (2015) Handbook of practical immunohistochemistry-Frequently asked questions. Springer, New York, Heidelberg, Dordrecht, London

32. Liu R, Xing M (2016) TERT promoter mutations in thyroid cancer. Endocr Relat Cancer 23:R143-R155

33. Lloyd RV, Osamura RY, Klöppel G, Rosai J (eds) (2017) WHO classification of tumours of endocrine organs, 4 edn. WHO classification of tumours, vol 10. IARC, Lyon

34. National Cancer Institute (2019) SEER cancer statistics review, 1975-2015. Seer cancer stat facts: Thyroid cancer

35. Nikiforov YE, Nikiforova MN (2011) Molecular genetics and diagnosis of thyroid cancer. Nat Rev Endocrinol 7:569-580

36. Nikiforov YE, Biddinger PW, Thompson LD (eds) (2012) Diagnostic pathology and molecular genetics of the thyroid. Lippincott Williams \& Wilkins, Philadelphia

37. Papotti M, Botto Micca F, Favero A et al (1993) Poorly differentiated thyroid carcinomas with primordial cell component. A group of aggressive lesions sharing insular, trabecular, and solid patterns. Am J Surg Pathol 17:291-301

38. Pilotti S, Collini P, Manzari A et al (1995) Poorly differentiatedforms of papillary thyroid carcinoma: Distinctive entities or morphological patterns? Semin Diagn Pathol 12:249-255

39. Pulcrano M, Boukheris H, Talbot M et al (2007) Poorly differentiated follicular thyroid carcinoma: prognostic factors and relevance of histological classification. Thyroid 17:639-646

40. Purkait S, Agarwal S, Mathur SR et al (2016) Fine needle aspiration cytology features of poorly differentiated thyroid carcinoma. Cytopathology 27:176-184

41. de Quervain F, Wegelin C (1936) Der endemische Kretinismus. Springer, Berlin, Wien

42. Rodrigues RF, Roque L, Rosa-Santos J et al (2004) Chromosomal imbalances associated with anaplastic transformation of follicular thyroid carcinomas. Br J Cancer 90:492-496

43. Saglietti C, Onenerk AM, Faquin WC et al (2017) FNA diagnosis of poorly differentiated thyroid carcinoma. A review of the recent literature. Cytopathology 28:467-474

44. Sakamoto A, Kasai N, Sugano H (1983) Poorly differentiated carcinoma of the thyroid. A clinicopathologic entity for a high-risk group of papillary and follicular carcinomas. Cancer 52:1849-1855 
45. Sanders EM Jr., Livolsi VA, Brierley J et al (2007) An evidence-based review of poorly differentiated thyroid cancer. World J Surg 31:934-945

46. Sasanakietkul T, Murtha TD, Javid M et al (2018) Epigenetic modifications in poorly differentiated and anaplastic thyroid cancer. Mol Cell Endocrinol 469:23-37

47. Schlumberger $M$, Tahara $M$, Wirth $L J$ et al (2015) Lenvatinib versus placebo in radioiodinerefractory thyroid cancer. $\mathrm{N}$ Engl J Med 372:621-630

48. Soares P, Lima J, Preto A et al (2011) Genetic alterations in poorly differentiated and undifferentiated thyroid carcinomas. Curr Genomics 12:609-617

49. Sobrinho-Simoes M (1996) Poorly differentiated carcinomasa of the thyroid. Endocr Pathol 7:99-102

50. Sugitani I, Kasai N, Fujimoto $Y$ et al (2001) Prognostic factors and therapeutic strategy for anaplastic carcinoma of the thyroid. World J Surg 25:617-622

51. Van Den Brekel MW, Hekkenberg RJ, Asa SL et al (1997) Prognostic features in tall cell papillary carcinoma and insular thyroid carcinoma. Laryngoscope 107:254-259

52. Viola D, Valerio L, Molinaro E et al (2016) Treatment of advanced thyroid cancer with targeted therapies: Ten years of experience. Endocr Relat Cancer 23:R185-205

53. Volante M, Collini P, Nikiforov YE et al (2007) Poorly differentiated thyroid carcinoma: The Turin proposal for the use of uniform diagnostic criteria and an algorithmic diagnostic approach. Am J Surg Pathol 31:1256-1264

54. Volante M, Rapa I, Papotti M (2008) Poorly differentiated thyroid carcinoma: Diagnostic features and controversial issues. Endocr Pathol 19:150-155

55. Volante M, Rapa I, Gandhi M et al (2009) RAS mutations are the predominant molecular alteration in poorly differentiated thyroid carcinomas and bear prognostic impact. J Clin Endocrinol Metab 94:4735-4741

56. Wreesmann VB, Ghossein RA, Patel SG et al (2002) Genome-wide appraisal of thyroid cancer progression. Am J Pathol 161:1549-1556

57. Yakushina VD, Lerner LV, Lavrov AV (2018) Gene fusions in thyroid cancer. Thyroid 28:158-167

58. Yang H, Chen Z, Wu M et al (2016) Remarkable response in 2 cases of advanced poorly differentiated thyroid carcinoma with liposomal doxorubicin plus cisplatin. Cancer Biol Ther 17:693-697

59. Zulewski H, Giovanella L, Bilz S et al (2019) Multidisciplinary approach for risk-oriented treatment of low-risk papillary thyroid cancer in Switzerland. Swiss Med Wkly 149:w14700 